Document downloaded from:

http://hdl.handle.net/10251/176525

This paper must be cited as:

Serra Alfaro, JM.; Borras-Morell, JF.; García-Baños, B.; Balaguer Ramirez, M.; Plaza González, PJ.; Santos-Blasco, J.; Catalán-Martínez, D.... (2020). Hydrogen production via microwave-induced water splitting at low temperature. Nature Energy. 5(11):910-919. https://doi.org/10.1038/s41560-020-00720-6

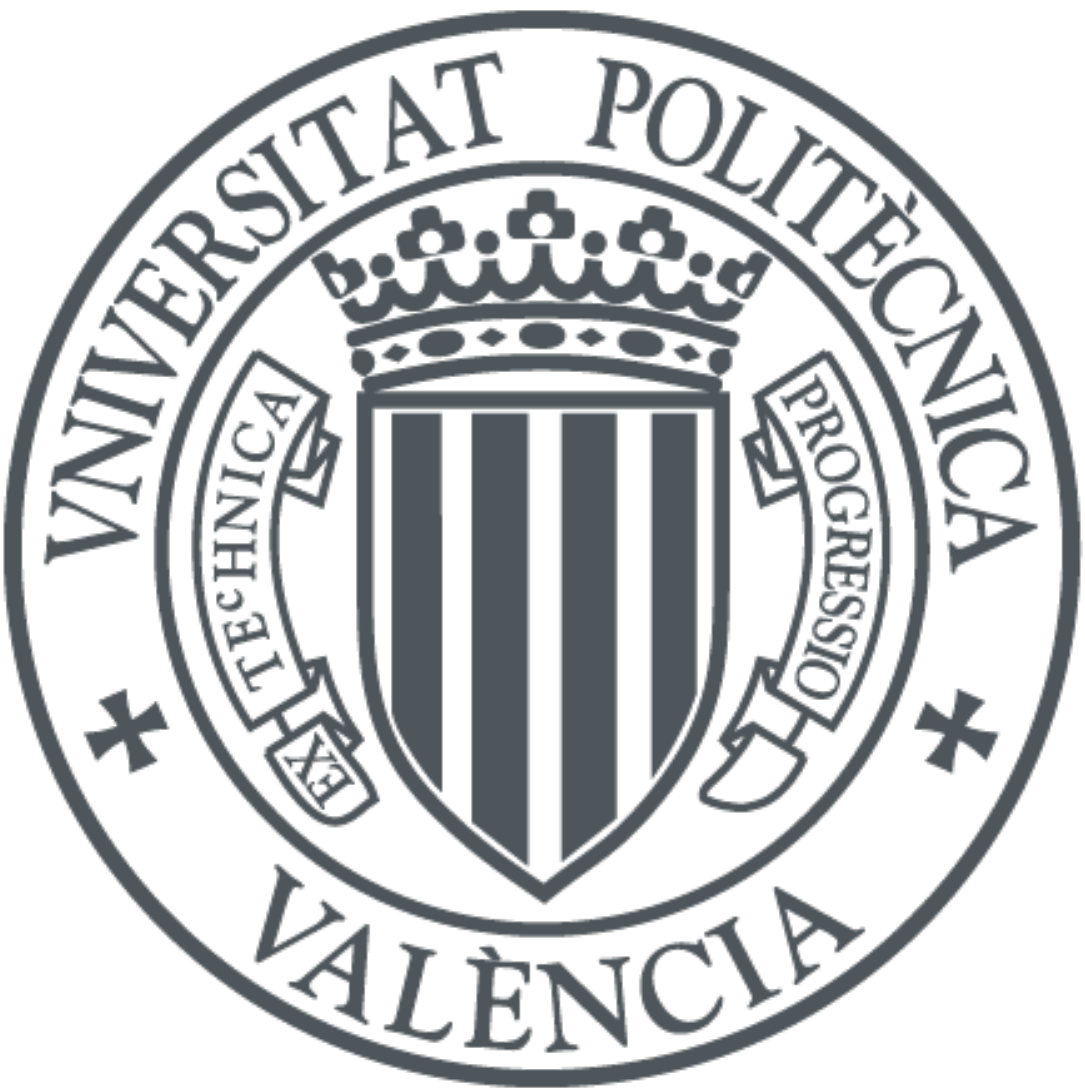

The final publication is available at

https://doi.org/10.1038/s41560-020-00720-6

Copyright Nature Publishing Group

Additional Information 


\title{
Hydrogen production via microwave-induced water splitting at low temperature
}

\author{
Authors: \\ J.M. Serra ${ }^{1 *}$, J.F. Borrás-Morell ${ }^{1,2}$, B. García-Baños ${ }^{2}$, M. Balaguer ${ }^{1}$, P. Plaza-González ${ }^{2}$, \\ J. Santos-Blasco ${ }^{1}$, D. Catalán-Martínez ${ }^{1}$, L. Navarrete ${ }^{1,2}$ and J.M. Catalá-Civera ${ }^{2 *}$ \\ ${ }^{1}$ Instituto de Tecnología Química, Universitat Politècnica de València-Consejo Superior \\ de Investigaciones Científicas, Avenida de los Naranjos s/n, Valencia,46022, Spain. \\ ${ }^{2}$ Instituto ITACA, Universitat Politècnica de València, Camino de Vera, Valencia, 46022, \\ Spain. \\ *Correspondence to: jmserra@itq.upv.es, jmcatala@dcom.upv.es.
}

Supplying global energy demand with $\mathrm{CO}_{2}$-free technologies is becoming feasible thanks to the rising affordability of renewable resources. Hydrogen is a promising vector in the decarbonization of energy systems, but more efficient and scalable synthesis is required to enable its widespread deployment. Here we report contactless $\mathrm{H}_{2}$ production via water electrolysis mediated by the microwavetriggered redox activation of solid-state ionic materials at low temperatures $(<250$ $\left.{ }^{\circ} \mathrm{C}\right)$. Water was reduced via reaction with non-equilibrium gadolinium-doped $\mathrm{CeO}_{2}$ that was previously in situ electrochemically deoxygenated by the sole application of microwaves. The microwave-driven reduction was identified by an instantaneous electrical conductivity rise and $\mathrm{O}_{2}$ release. This process was cyclable, whereas $\mathrm{H}_{2}$ yield and energy efficiency were material- and power-dependent. Deoxygenation of low-energy molecules $\left(\mathrm{H}_{2} \mathrm{O}\right.$ or $\left.\mathrm{CO}_{2}\right)$ led to the formation of energy carriers and enabled $\mathrm{CH} 4$ production when integrated with a Sabatier reactor. This method could be extended to other reactions such as intensified hydrocarbons synthesis or oxidation.

Sustainability of industry, transportation and energy management will rely on $\mathrm{CO} 2$-free technologies and renewable electricity, which are boosted by the rising affordability of photovoltaic solar and wind turbine parks. The electrification of industry and transport will strongly contribute to limiting greenhouse gas emissions ${ }^{1,2}$ by using $\mathrm{CO}_{2}$-neutral energy carriers or chemical raw materials; however, the intermittent nature of renewables 
requires new energy storage tools paired with novel, highly efficient methods to electrify unitary steps in process industry ${ }^{3,4}$.

Batteries and water electrolysers enable the compact, scale-flexible and durable storage of electric energy. The storage of energy in the $\mathrm{H}_{2}$ molecule is of great interest as it can be converted back into electricity in a fuel cell or used in chemical processing. $\mathrm{H}_{2}$ production today is mostly accomplished by reforming hydrocarbons, leading to a substantial $\mathrm{CO}_{2}$ footprint. $\mathrm{H}_{2}$ produced from water and green power through solar thermochemical or photocatalytic water splitting ${ }^{5,6}$ and water electrolysis ${ }^{7-9}$ has become a sustainable alternative with negligible on-site greenhouse gas contribution. In thermochemical cycles, the highly energy-demanding splitting of water molecules $\left(\triangle H_{H 2 O}=285 \mathrm{~kJ} \mathrm{~mol}^{-1}\right)$ is often realized by using regenerable energy carriers (molecular or solid agents as metals or ceramics) that reduce water to yield $\mathrm{H}_{2}$. The redox activation of water is usually carried out by very high-temperature heating or galvanic methods to enable this non-spontaneous equilibrium-limited reaction, that is, with a large positive Gibbs free-energy change $\left(\Delta G_{H 2 O}\right)$.

Electromagnetic processes such as microwave heating hold promise for smart manufacturing and activating chemical reactions ${ }^{10,11}$, and can enable electrochemical operation without contact electrodes and the restrictions of conventional electrolysis cells, those being constrained operation conditions and equipment complexity. Here we report the contactless $\mathrm{H}_{2}$ production from water, mediated by microwave-triggered redox activation of solid-state ionic materials. Water splitting is realized by the sole application of microwave radiation, which enables the chemical redox cycling (Fig. 1) of ceramic oxides at very low temperatures $\left(<250{ }^{\circ} \mathrm{C}\right)$. In the first step, microwaves interact with the crystalline oxide, leading to an instantaneous rise in electrical conductivity that is accompanied by the material reduction (deoxygenation). This electromagnetically driven reduction mechanism implies that the electron transfer couples with solid-state oxide-ion diffusion and surface release of molecular oxygen to result in a non-equilibrium highenergy state. The second step involves splitting water through a spontaneous reaction with the activated material, which leads to direct $\mathrm{H}_{2}$ formation and reoxygenation of the material. This striking reaction can also be applied to the reduction of other oxidized molecules to directly produce different molecular energy carriers, that is, converting $\mathrm{H}_{2} \mathrm{O}$ and $\mathrm{CO}_{2}$ into syngas that can in turn be transformed into hydrocarbons. This versatile technique opens the door to new, simpler and energy-efficient routes for $\mathrm{H}_{2}$ production 
and the non-invasive electrification of catalytic reactions such as hydrocarbon synthesis and selective oxidations, along with gas separations ${ }^{12}$ and solid-state energy storage ${ }^{13}$.

\section{Hydrogen synthesis from microwave energy}

To explore the coupled water splitting and redox cycling of oxide materials, we developed an ad hoc cavity and a new method grounded on precisely controlled microwave irradiation. The experiments were carried out in a continuous flow-through tubular quartz reactor holding a packed-bed reactor; the reactor was inserted into the microwave resonant-mode cylindrical cavity, which is capable of reaching temperatures of up to $1,000{ }^{\circ} \mathrm{C}$ under different gas atmospheres. The set-up (Fig. 2a) was completed with a 120 W solid-state microwave generator and control system $(\sim 2.45 \mathrm{GHz})$, an infrared pyrometer, on-line gas analysis and a probe for in situ conductivity measurement in the same cavity, using an additional orthonormal polarized E-field configuration connected to a second low-power microwave source at close frequencies ${ }^{14}$. The average bulk temperature of the sample is determined by monitoring the pyrometer-based surfacereactor temperature, with extensive calibration procedures, which included an optic fibre within the material (see Supplementary Fig. 1) ${ }^{15}$. The theoretical modelling of the electromagnetic field distribution (Fig. 2a) within the resonant cavity evidences the intense and uniform irradiation of materials inside of the reactor.

Doped $\mathrm{CeO}_{2}$ is used to illustrate the microwave redox principle as this well-studied ionconductor is catalytic ${ }^{16,17}$ and chemically reducible while structurally very stable. Figure $2 \mathrm{~b}$ shows the time evolution of temperature and gas composition during the microwave treatment of $\mathrm{Ce}_{0.8} \mathrm{Gd}_{0.2} \mathrm{O}_{1.9}$ (CGO) under dry $\mathrm{N}_{2}$ flow. The controlled microwave application heats the material up to an induction temperature $\left(\mathrm{T}_{\text {ind }} \approx 110^{\circ} \mathrm{C}\right)$, from which the material capability to absorb microwave energy is largely increased. At this point, the radiation triggers the material reduction for supplied power values above an absorption threshold $\left(P_{t h} \approx 10 \mathrm{~W} \mathrm{~g}^{-1}\right)$, as revealed by the sharp $\mathrm{O}_{2}$ release monitored by mass spectrometry, achieving $>0.2 \mathrm{ml} \mathrm{O}_{2}$ per gram of solid. By contrast, conventional heating shows negligible $\mathrm{O}_{2}$ release in this operation range (Supplementary Fig. 2), requiring challenging temperatures $\left(>1,100{ }^{\circ} \mathrm{C}\right)$ for an equivalent reduction in solar thermochemical cycles ${ }^{18,19}$. Following reduction, the controlled microwave irradiation produces the steeply and continuous heating up to a final equilibration temperature $\left(T_{e q}\right)$, where the absorbed microwave power per unit mass $\left(P_{M W}\right)$ is adjusted to preserve the non- 
equilibrium material state at constant $T_{\text {eq }}$. This abrupt reduction is attributed to the effect of the strong electromagnetic polarization of the material at low temperatures (below 200 $\left.{ }^{\circ} \mathrm{C}\right)$. Despite precise calibration of the temperature measurement ${ }^{15}$, a massive temperature gradient among the material fixed-bed reactor could not, however, explain the narrow time distribution of the observed $\mathrm{O}_{2}$ formation in Fig. 2b nor why no further $\mathrm{O}_{2}$ is measured up to $T_{e q}$. A progressive $\mathrm{O}_{2}$ release would be expected for a microwave-driven purely thermal reduction effect (demanding peak temperatures $>1,100{ }^{\circ} \mathrm{C}$ ). On the contrary, here the sample was heated up to $750{ }^{\circ} \mathrm{C}$ without additional $\mathrm{O}_{2}$ formation. The microwave power effect on the heating dynamics was analysed by radiating at constant absorbed power a CGO sample initially set at $200{ }^{\circ} \mathrm{C}$ in an oxidizing atmosphere (Supplementary Fig. 3). Although a large sharp temperature step-rise is found for power rates above the threshold, a smooth, damped distribution is reported otherwise without any sign of $\mathrm{O}_{2}$ release. In the transition scenario (where controlled absorbed power is approximately equal to $P_{t h}$ ), a small variation of the energy input leads to an immediate, severe temperature response, and yet is incompatible with a delay on bulk-surface activation times or overheated bulk regions. This very dissimilar heating behaviour can only be ascribed to the high-frequency strong polarization that the microwave-induced electromagnetic field causes on the material, triggering its reduction, as reported in direct current-polarized solid-oxide electrochemical cells ${ }^{20}$. In situ conductivity measurements shed further light on the nature of this effect.

\section{Conductivity analysis}

It has been largely reported that the reduction of ceria-based materials has a direct effect on their electrical properties ${ }^{21}$. Charge-carrier transport mechanisms within the microwave-irradiated material were further investigated by contactless alternating current conductivity measurements during simultaneous microwave application (see Supplementary Notes 4-6). Following conventional heating, the conductivity (Fig. 2c) follows an Arrhenian behaviour that is characteristic of prevailing oxide-ion conduction, with an activation energy $E_{A, i o n} \approx 0.42 \mathrm{eV}$. However, the microwave-irradiated material exhibits two distinctive electrical conductivity profiles, depending on whether the applied power is above/below $P_{t h}$ (Fig. 2c,d). At $P_{M W}>P_{t h}$, an instantaneous conductivity growth is observed on reaching $T_{\text {ind }}$ (Fig. 2c), unveiling a characteristic transition step simultaneous to $\mathrm{O}_{2}$ release. Following nearly full $\mathrm{O}_{2}$ release, further conductivity growth 
with temperature is mostly related to the thermal activation of both charge carriers (oxygen vacancies and electrons), reflecting an initial electronic conduction character that becomes gradually more dominated by oxide-ion transport as temperature increases (Supplementary Fig. 4). Once the microwave power has ceased, the cooling process occurs as in a conventional heating cycle. The application of an external electric field transforms both material oxygen substoichiometry $(\delta)$ and charge-carrier mobility. First, the microwave-induced material reduction leads to the formation of one oxygen vacancy and two localized electronic charge carriers (polarons ${ }^{22}$ ) per pair of reduced ceria atoms $\left(\mathrm{Ce}^{4+} \rightarrow \mathrm{Ce}^{3+}\right)$. The oxygen vacancy concentration, as well as the associated ionconductivity, rise a modest $10 \%$, as quantified from the $\mathrm{O}_{2}$ release. The homologous growth of the electronic carrier population translates, however, into a much greater increment of the electronic conductivity (that is, proportional to $\left[\mathrm{Ce}^{3+}\right]$ ); namely, a twoorder of magnitude enhancement for $30 \mathrm{~W} \mathrm{~g}^{-1}$ (Fig. 2c). Second, the polaron mobility is boosted, even if the relative orientation of the polaron hopping trajectory is different from the E-field direction and apparently arbitrary, as reported for polaronic transport in disordered organic solids ${ }^{23}$. The activation energy for n-type polaron mobility reveals a considerable decrement in the presence of microwave-assisted E-fields, $E_{A, n}=0.19 \mathrm{eV}$ (fitting in Supplementary Fig. 4).

The conductivity at $P_{M W}<P_{t h}$ displays a monotonic Arrhenian evolution with neither abrupt transitions nor signs of $\mathrm{O}_{2}$ release (Fig. 2d and Supplementary Fig. 2c,d). Still, a moderate conductivity increment is detected during microwave heating compared with conventional heating. Hence, microwave radiation seems to promote polaron mobility with an increasing influence of the applied E-field magnitude albeit the power was not sufficient to trigger the material reduction. This agrees with the Poole-Frenkel effect in polaronic materials, that is, moderate E-fields trigger the direct decline in hopping activation energy and long-range electron-phonon interaction enhancement that underpins polaron migration ${ }^{24}$. Following E-field cessation, electronic mobility is no longer activated, as revealed by the observed patterns during cooling and conventional heating.

Microwave-assisted reduction alters the lattice structure and electronic configuration of CGO. X-ray photoelectron spectroscopy of activated CGO confirms the formation of surface oxygen vacancies and $\mathrm{Ce}^{3+}$ on irradiation, with $\mathrm{Ce}^{3+} / \mathrm{Ce}^{4+}$ surface ratio $\sim 27 \%$ (Supplementary Fig. 5). Compared with $\sim 2.6 \%$ average ratio inferred from the total 
oxygen released, the redox process reveals a superior activity on the grain surface level. The $\mathrm{Ce}^{3+}$ appearance lowers the narrow band of $4 f$ electronic states localized around the $\mathrm{Ce}^{3+}$ sites, giving rise to a reduced band gap (a colour change to blue in Fig. 2e) as determined by UV-vis spectroscopy and is also reflected in the increased cell parameter of the fluorite host (Supplementary Fig. 5).

\section{Energy analysis}

The applied microwave power is absorbed through two coupled phenomena, that is, the endothermic oxygen vacancy formation $\left(\Delta H_{r}=385 \mathrm{~kJ} \mathrm{~mol}^{-1} \text { for CGO }\right)^{25,26}$ and the heating induced by the agitation and vibration of the crystalline lattice (Fig. 2f). CGO reduction is not spontaneous $\left(\Delta G_{r}>0\right)$ for the studied temperature range $\left(200-500^{\circ} \mathrm{C}\right)$ and only takes place by microwave-triggered electrochemical induction. This leads to a more disordered system through formation of gaseous $\mathrm{O}_{2}$ and oxygen vacancies in non-preferential lattice sites. The heat demand associated with this entropy increment $\left(T \Delta S_{r}\right)$ can be partially or fully satisfied by the simultaneous microwave heating and thus the net energy demand of the material reduction is the Gibbs free-energy, which is readily provided by the microwave radiation.

Low-energy molecules can be reduced by the redox-activated material through a deoxygenation pathway, as exemplified in Fig. $3 \mathrm{a}$ for the conversion of $\mathrm{H}_{2} \mathrm{O}$ into valuable $\mathrm{H}_{2}$. Under a wet gas flow $\left(3 \% \mathrm{H}_{2} \mathrm{O}\right.$ in $\left.\mathrm{N}_{2}\right)$, CGO was first microwave reduced $\left(T_{e q}<400\right.$ ${ }^{\circ} \mathrm{C}$ ) and the released $\mathrm{O}_{2}$ molecules were evacuated. Figure $3 \mathrm{~b}$ represents the time sequence of $\mathrm{O}_{2}$ and $\mathrm{H}_{2}$ gas generation, temperature variation, total absorbed power $\left(P_{a b s}\right)$ and electric conductivity. After initial heating until $T_{\text {ind }}$, and applying the absorbed power above the threshold (from 10 to $40 \mathrm{~W} \mathrm{~g}^{-1}$ ), a reduction outbreak and a huge rise in conductivity are observed. The induced microwave E-field preserves the nonequilibrium, reduced state; however, once microwaves are switched off, the material reoxidizes by reacting with water, evolving gaseous $\mathrm{H}_{2}$. This water splitting mechanism is experimentally confirmed via the formation of $\mathrm{D}_{2}$ when using $\mathrm{D}_{2} \mathrm{O}$ instead of $\mathrm{H}_{2} \mathrm{O}$. The mass spectrometer signals for both $\mathrm{H}_{2} \mathrm{O}$ and $\mathrm{D}_{2} \mathrm{O}$ experiments display a similar behaviour (Fig. 3c), that is, first the $\mathrm{O}_{2}$ release is observed $(\mathrm{m} / \mathrm{z}=32)$ and, on modulation of microwave power, the material is reoxygenated by reaction with water, as evidenced by formation of $\mathrm{H}_{2}$ or $\mathrm{D}_{2}(\mathrm{~m} / z=4)$. Unquestionably, the production of $\mathrm{H}_{2}$ in the system stems from the CGO reoxidation and the consequent water splitting. Figure $3 \mathrm{~d}$ shows the time 
evolution of temperature and gas formation for sequential microwave-driven $\mathrm{H}_{2} \mathrm{O}$ deoxygenation cycles (eight cycles). $\mathrm{H}_{2}$ production reflects high stability and excellent process reproducibility (Supplementary Fig. 6), as further confirmed by the subsequent $\mathrm{O}_{2} / \mathrm{H}_{2}$ balances comparison (that is, $\sim 1.1 \mathrm{ml}\left(\mathrm{H}_{2}\right)$ per cycle) being moderately incremented for larger $p_{H 2} \mathrm{O}$. We envision that this reductive process can be further integrated with synthesis catalysts to directly produce hydrocarbons from $\mathrm{CO}_{2}$. For instance, simultaneous deoxygenation of $\mathrm{H}_{2} \mathrm{O}$ and $\mathrm{CO}_{2}$ to produce syngas can be widely employed in the synthesis of added-value chemicals, for example, via the FischerTropsch or methanol-intermediate routes.

The excellent process cyclability will enable continuous $\mathrm{H}_{2}$ production through two different configurations (Fig. 4): microwave-swing reactors and a chemical looping scheme ${ }^{27}$. In the swinging process, the material remains fixed while reduction and $\mathrm{H}_{2}$ formation (reoxidation) steps take place separately in two alternating reactors. The regime of each reactor is exchanged in consecutive cycles. In chemical looping, the material is closed-loop flowing and the reactors operate continuously in the same regime producing two separate streams of $\mathrm{O}_{2}$ and $\mathrm{H}_{2}$.

\section{Thermodynamic evaluation}

To assess the practical implications of microwave-assisted $\mathrm{H}_{2}$ production, we performed thermodynamic process simulations and evaluated the energy efficiency. We assumed that microwave radiation is mostly absorbed by the material (90-95\%, with irradiation losses within the 5-10\% range; see Supplementary Note 11) and serves as both main energy source and electrochemical driving force. This absorbed power promotes simultaneous material reduction and heating, with the energy fraction absorbed by the reduction defined as $f_{r}$ (Fig. 2f), whereas the heating fraction is $1-f_{r}$. The subsequent material reoxidation and water splitting to form $\mathrm{H}_{2}$ is spontaneous if the free Gibbs energy level reached by the material in the reduction stage $\left(\Delta G_{r}\right)$ exceeds the water dissociation energy along the redox cycle (that is, $\Delta G_{r}>\Delta G_{H 2 O}$ ). The energy balance in Fig. 5 schematizes the scenario where the difference between the enthalpies of oxygen vacancy generation and water dissociation is exothermic (that is, $\Delta H_{r}>\Delta H_{H 2 O}$ ), and this heat surplus from $\mathrm{H}_{2}$ production can be recovered in the next endothermic reduction cycle or, alternatively, to produce overheated steam. 
The energetic evaluation for the complete redox loop (Fig. 5) considers the $\mathrm{H}_{2}$ yield to be determined by the equilibrium, that is, by the net change in oxygen substoichiometry $\left(\Delta \delta_{\text {loop }} \equiv \delta_{r}-\delta_{o x}\right.$ in $\left.M O_{x-\delta r} \leftrightarrow M O_{x-\delta o x}\right)$. For operation with the CGO material ${ }^{25,26}$, the highest boundary in energy efficiency (Fig. 5b) is reached when only the electric microwave energy demand is accounted and scales linearly with $f_{r}$. The lowest boundary is reached when considering the complete energy demand of the balance of plant, that is, steam generation from liquid water. The actual energy efficiency lies between these boundaries (grey zone) and depends on the degree of heat recovery from the exothermic reoxidation step into the balance of plant heat demand. These results show the critical impact of $f_{r}$ in the process efficiency. The energy cost evaluation of $\mathrm{H}_{2}$ production (Fig. $5 \mathrm{c}$ and Supplementary Fig. 7a) using three different materials (namely, $\mathrm{CGO}$, pure $\mathrm{CeO}_{2}$ and $20 \% \mathrm{ZrO}_{2}$-doped $\left.\mathrm{CeO}_{2}(\mathrm{CZO})\right)$ illustrates the marked effect of the dopant nature and initial oxygen substoichiometry $\left(\delta_{0}\right)$. The lesser energy requirement of $\mathrm{CeO}_{2}$ and, particularly, CZO originates from its lower reduction enthalpy $\left(\Delta H_{r}\right)$. For $\mathrm{CZO}$, the stepcoupling $\mathrm{H}_{2}$ formation and material reoxygenation becomes endothermic $\left(\Delta H_{r}>\Delta H_{H 2 O}\right)$, demanding additional heat from, for example, microwave heating $\left(1-f_{r}\right)$. Furthermore, the reducibility of the oxides is different: higher $\delta_{r}$ values are reached for $\mathrm{CeO}_{2}$ and $\mathrm{CZO}$ even at lower temperatures; however, only a fraction of these vacancies is capable of reducing $\mathrm{H}_{2} \mathrm{O}$, CGO being the most reductive agent (Supplementary Fig. 7b). The activated CGO can be nearly fully reoxidized by steam and the experimentally observed values for the closed-loop variation of oxygen vacancy fraction $\left(\Delta \delta_{\text {loop }}\right)$ range between 0.002 and 0.005, in line with thermodynamic calculations, whereas $\mathrm{CZO}$ and $\mathrm{CeO}_{2}$ can only be partly reoxidized by steam. The distinct impact of the oxygen vacancy formation in the lattice entropy is responsible for the dissimilar redox behaviours.

Figure 5d compares the operating energy costs with three established technologies for $\mathrm{H}_{2}$ production from water: electrolysis plants based on (1) alkaline ${ }^{28-32}$ and (2) proton exchange membrane (PEM) cells ${ }^{28-30,33}$, and (3) a solar thermochemical plant that is based $^{30,34,35}$ on ceria and perovskite oxides. These technologies will be among the most competitive in likely scenarios featuring abundant and low-cost renewable electricity and rising $\mathrm{CO}_{2}$ taxation $^{8,36}$. Currently, PEM water electrolysis holds the highest share in this quickly evolving market due to its high energy efficiency and simple equipment operability. The quantitative analysis of the operating energy costs (Fig. 5d) reveals that microwave technology can be a competitive technology in the future with respect to 
conventional water electrolysis techniques. The capital cost estimation, evaluated for two different scales (distributed and centralized $\mathrm{H} 2$ production, with $10 \mathrm{~kg}$ and 50,000 $\mathrm{kg}$ per day, respectively) at present and future scenarios, also forecasts comparable capital expenses (Supplementary Fig. 7); however, microwave energy must be selectively used in the reduction of the oxide $\left(f_{r}>0.7\right)$ to reach the lowest $\mathrm{H}_{2}$ operating energy costs. Furthermore, the microwave technology can potentially reach higher efficiency than the experimental solar thermal process, directly generating $\mathrm{H}_{2}$ at operational temperatures $>1,200{ }^{\circ} \mathrm{C}$, reached by efficiently concentrating sunlight ${ }^{37}$.

\section{Intensification of processes assisted by microwaves}

Beyond $\mathrm{H}_{2}$ production, the broad applicability of microwave-driven reduction of different oxides in the intensification of chemical process is here exemplified by the selective (Sabatier) $\mathrm{CH}_{4}$ formation ${ }^{38}$ starting from $\mathrm{H}_{2} \mathrm{O}$ and $\mathrm{CO}_{2}$ (Fig. 6a), accomplished using a $\mathrm{Ru} / \gamma-\mathrm{Al}_{2} \mathrm{O}_{3}$-catalyst packed-bed reactor in series with the microwave cavity. Before the methanation reaction, the dry $\mathrm{CO}_{2}$ deoxygenation was independently studied with a constant flow of $15 \%$ of $\mathrm{CO}_{2}$ in argon. Reproducible behaviour was obtained for nine cycles, as for the studied $\mathrm{H}_{2} \mathrm{O}$ deoxygenation, that is, an initial $\mathrm{O}_{2}$ release reveals the microwave-assisted oxide reduction and then-following microwave cessation- $-\mathrm{CO}_{2}$ is partly converted into $\mathrm{CO}$ (Supplementary Fig. 8), as revealed by the $\mathrm{CO}_{2}$ signal diminution and the $\mathrm{CO}$ signal growth. The simultaneous deoxygenation of $\mathrm{H}_{2} \mathrm{O}$ and $\mathrm{CO}_{2}$ to yield $\mathrm{CO}$ and $\mathrm{H}_{2}$ was first investigated (Supplementary Fig. 9a) for consecutive cycles using a constant flow of $15 \% \mathrm{CO}_{2}$ and $3 \% \mathrm{H}_{2} \mathrm{O}$ (argon balance) and by analysing the cavity-outlet gas. During the reduction step, together with the $\mathrm{O}_{2}$ release, a thermalinduced desorption of $\mathrm{CO}_{2}$ from the material surface was observed at $>150{ }^{\circ} \mathrm{C}$. Following microwave shutoff, $\mathrm{CO}$ and $\mathrm{H}_{2}$ were formed and $\mathrm{CO}_{2}$ was converted while $\mathrm{CH}_{4}$ could not be detected at this stage. The in-line catalytic treatment of this gas stream in the sequential isothermal reactor gave rise to the formation of $\mathrm{CH}_{4}$ and high conversion of $\mathrm{CO}$ and $\mathrm{H}_{2}$ (Fig. 6b and Supplementary Fig. 9b), pointing out the high cyclability of this hybrid microwave-redox catalytic process. $\mathrm{CH}_{4}$ formation over the $\mathrm{Ru}^{0}$ surface can proceed via hydrogenation of $\mathrm{CO}$ intermediate, coupled with the reverse water-gas shift reaction or via direct $\mathrm{CO}_{2}$ hydrogenation ${ }^{39}$. 
The unique ability of microwave radiation to evolve $\mathrm{O}_{2}$ and transmute the redox catalytic behaviour in oxides can eventually be leveraged to in situ realize the selective hydrocarbon oxidation or complete combustion of hydrocarbons, for example, $\operatorname{soot}^{40}$ or VOCs $^{41}$ abatement. Figure $6 \mathrm{c}, \mathrm{d}$ shows the syngas production via $\mathrm{CH}_{4}$ partial oxidation ${ }^{42}$. Under a $10 \% \mathrm{CH}_{4}$ stream on reaching $T_{\text {ind }}, \mathrm{CH}_{4}$ reacts with surface oxygen species evolving from the activated $\mathrm{CeO}_{2}$ lattice ${ }^{43}$ and is primarily converted into $\mathrm{H}_{2}, \mathrm{CO}$ and $\mathrm{CO}_{2}$ while $\mathrm{O}_{2}$ traces are still detectable (Supplementary Fig. 10). The high degree of process intensification reached here, that is doped $\mathrm{CeO}_{2}$ plays a triple role by acting as redox-activated catalyst, microwave-modulated oxygen carrier and by locally providing the thermal energy for the reaction light-off, will enable the development of new chemical looping schemes ${ }^{27}$.

\section{Conclusions}

A carbon-free $\mathrm{H}_{2}$ production method is reported. Under microwave mediation, solid-state ionic materials are redox activated at very low temperatures. The observed reduction is triggered on a given $T_{\text {ind }}$ and for a supplied microwave intensity above a certain power threshold (both of which are material-dependent properties), as ascertained from an abruptly peaked oxygen release and a large characteristic electronic conductivity raise. We derive that the material's capacity to absorb energy is temperature activated and the reported redox phenomena and the electronic dynamics are highly stimulated by highfrequency polarization effects caused by the induced electromagnetic field. The production of $\mathrm{H}_{2}$-accomplished via water splitting and prompted by the material reoxygenation-manifests as a reversible, cyclable process. Furthermore, the proposed technology can be coupled to produce different hydrocarbons or other molecular energy carriers, for example, the reported $\mathrm{CH}_{4}$ formation from $\mathrm{CO}_{2}$ and $\mathrm{H}_{2} \mathrm{O}$ integrated in a Sabatier reactor over a $\mathrm{Ru} / \gamma-\mathrm{Al}_{2} \mathrm{O}_{3}$-catalyst.

From the thermodynamic analysis of the redox process, $f_{r}$ (the fraction of absorbed microwave energy leveraged to promote the material reduction) emerges as the critical parameter that regulates the energy efficiency of the redox process and the hydrogen production cost. Heat losses and the energy balance of the plant can be often covered by the material heating excess, $1-f_{r}$. Furthermore, the preference of CGO over the other studied materials originates from its greater reductive power, as the larger amount of oxygen vacancies generated are capable of deoxygenating water. The proposed 
microwave-driven technology opens a new pathway for energy storage that is already expected to be competitive with conventional water electrolysis technologies.

This method enables the contactless, electrolyte-free realization of electrochemical reactions such as $\mathrm{H}_{2} \mathrm{O}$ electrolysis, alleviating the operational constraints of classical electrochemical cells (that is, the temperature, pressure and reactor-stack architecture will not be restricted by the electrolyte/electrode operation window and challenging electric contacting). Reduction of compounds based on anions other than $\mathrm{O}^{2-}$ (for example, $\mathrm{S}^{2-}$, $\mathrm{Cl}^{-}, \mathrm{Br}^{-}$) will allow for new chemistries, with application in several sectors such as emission control $^{44}$ and functionalization of hard-to-activate molecules at low temperatures ${ }^{45}$. Electricity storage is another pivotal application, facilitating ultrafast battery recharge $\mathrm{e}^{28,29}$ through volumetric reduction of anode-chamber materials. Tighter control of reduction energetics (electric work and reduction/reoxidation enthalpies) through material formulation and microwave-process engineering will maximize energy efficiency and operability in very diverse areas.

\section{Methods}

Materials preparation. $\mathrm{Ce}_{0.8} \mathrm{Gd}_{0.2} \mathrm{O}_{2-\delta}$ (CGO) was purchased from Cerpotech (Norway). The asreceived powders were pre-annealed at $1400{ }^{\circ} \mathrm{C}$ and sieved between 200 and $250 \mu \mathrm{m}$. CGO powders for methanation experiments were synthesized via the co-precipitation method ${ }^{21}$, followed by calcination in air at $600{ }^{\circ} \mathrm{C}$, delivering a crystallite size below $40 \mathrm{~nm}$.

Microwave irradiation of samples. The microwave cylindrical cavity $(104.92 \mathrm{~mm}$ in diameter, $85 \mathrm{~mm}$ in height) was designed to irradiate samples of solid materials and perform simultaneous in situ measurements of the alternating current conductivity. The cavity has open cut-off holes in the upper, lower and lateral walls for insertion of the pass-through tubular quartz reactor containing the sample, location of antennas for coupling of microwaves, and process monitoring. The set-up was completed by a $120 \mathrm{~W}$ solid-state microwave amplifier (RCA2026U50, RFcore Ltd., from 2.2 to $2.6 \mathrm{GHz}$ ) driven by the oscillator and receiver of a network analyser (Rohde \& Schwarz ZVRE) and a microwave control system.

The microwave control system-located next to the irradiation source (amplifier) in the experimental set-up - made use of a variable coupling device (coaxial probe with variable penetration) and a double directional coupler (Meca Electronics, model 722-40-1.950 W) to adjust and measure the reflected signals from the microwave cavity as a function of frequency and temperature to provide the desired level of heating rate to the sample. This configuration enables 
temperatures to reach higher than $1,000{ }^{\circ} \mathrm{C}$ in the sample under different gas atmospheres. To determine the bulk temperature of the sample, the surface temperature of the quartz reactor was measured by an infrared pyrometer (Optris CT-Laser LT), previously calibrated with multiple procedures including measurements of fibre optic sensors placed in contact with the material's body (see the Suppementary Methods for the full method).

The irradiation of solid materials (in a tubular volume of $9.8 \mathrm{~mm}$ in diameter and $15 \mathrm{~mm}$ in height) was realized through the application of microwave power in the cylindrical transversal electric mode $\mathrm{TE}_{111}$ around the ISM (industrial, scientific and medical) frequency of $2.45 \mathrm{GHz}$.

Measuring the alternating current conductivity of samples. For microwave conductivity measurements (alternating current conductivity) of samples during microwave irradiation, the microwave source and receiver of an additional low-power vectorial network analyser (Hewlett Packard HP8720E) were coupled to the microwave cavity through the SubMiniature version A connector placed at the bottom wall of the cavity. The continuous sweep of the generator frequencies from $1.9 \mathrm{GHz}$ to $2.2 \mathrm{GHz}$ and received signals allowed extraction of the cavity resonance response of the electromagnetic cylindrical mode $\mathrm{TM}_{010}$, employed for conductivity calculations. The dual-mode configuration (microwave heating and simultaneous conductivity measurements) was feasible without interferences by using two different microwave sources at slightly different microwave frequencies and a high isolation cross-coupling filter ${ }^{14}$.

Alternating current conductivity measurements. Conductivity measurements of solid materials at microwave frequencies (alternating current conductivity) as a function of temperature were based on the microwave cavity perturbation technique ${ }^{46}$ and rely on the fact that the introduction of a small sample in a resonant cavity barely perturbs the microwave electromagnetic fields around the material. The method requires the measurement of the resonance characteristics of the microwave cavity (that is, the resonance frequency and the $Q$ factor) from the second microwave system coupled to the bottom of the cavity (measurement mode $\mathrm{TM}_{010}$ ). These are measured before the insertion of the material sample, after the insertion of the empty quartz reactor inside of the cavity, and continuously during the microwave irradiation of the sample (and the quartz reactor) in the cavity. The observed variations in frequency and $\mathrm{Q}$ factor ${ }^{14}$ ( $\Delta f / f$ and $\Delta\left((2 Q)^{-1}\right)$, respectively) lead to the evaluation of the alternating current conductivity as

$$
\sigma_{A C}=\omega \varepsilon_{0} \frac{\eta \Delta\left(\frac{1}{2 Q}\right)}{\left(\eta+N \frac{\Delta f}{f}\right)^{2}+N^{2}\left[\Delta\left(\frac{1}{2 Q}\right)\right]^{2}},
$$


where $\omega$ is the angular frequency of the microwave signal; $\varepsilon_{0}$ is the vacuum permittivity; and $N=0.102$ and $\eta=0.00238$ are the sample depolarization factor in the direction of the electric field polarization and the sample filling factor that quantifies the electric relative volume sample/cavity, respectively ${ }^{47}$, which depended on the specific geometry of the cavity, the resonant mode $\left(\mathrm{TM}_{010}\right)$ and sample, and were determined through a calibration by measuring reference materials with known permittivity ${ }^{14}$.

To enable the analysis of the polarization mechanism of the material, measurements of conductivity and dielectric properties variations are performed in the same frequency range (gigahertz) as the frequency of the irradiation $(\sim 2.45 \mathrm{GHz})$. Consequently, frequency of the measurement mode emerges as a dependent variable in the current experimental configuration and broadband frequency range experiments are not currently available, for example, the impedance response of the material for different frequencies (see Supplementary Notes 6 and 7).

Measurement using conventional heating. For alternating current conductivity measurements under conventional heating, an electric resistance furnace was employed above the cylindrical cavity $^{48}$ (see Supplementary Note 3 ). Small cylindrical samples of particulate materials $(9.8 \mathrm{~mm}$ diameter and $15 \mathrm{~mm}$ height) were placed on a quartz frit membrane located in a long tubular quartz reactor and heated in the furnace outside of the cavity. Once the desired temperature was reached in the furnace, the reactor containing the sample was moved to the cavity for the conductivity measurements and then rapidly moved back to the furnace to continue with the heating process.

Microwave heat generation and control. The microwave power absorbed by the sample was adjusted by fixing the coupling device to a specific penetration and dynamically selecting the frequency sweeps of the microwave source around the frequency peak of the cavity, as the heating of the sample was progressing. Then, by selecting the appropriate frequency sweeps of the microwave source around the frequency peak of the cavity $\left(f_{l}\right.$ and $\left.f_{N}\right)$, the required level of microwave power (average microwave power) can be provided to the microwave reactor according to a desirable heating rate $\left(\mathrm{K} \mathrm{s}^{-1}\right)$. The full development of the method is shown in Supplementary Methods.

Temperature calibration. An infrared pyrometer (Optris CT-Laser LT) with an accuracy of 0.1 ${ }^{\circ} \mathrm{C}$ was used to determine the bulk temperature of the sample by measuring the surface temperature of the quartz reactor from outside of one of the microwave cavity access holes (see Supplementary Fig 2). The surface temperature of the quartz reactor is normally the coolest region on the material volume due to the inverted temperature profiles in microwave heating processes. 
A calibration is therefore needed to determine the correspondence between the measured temperature (quartz surface) and the sample bulk temperature (at which the reactions take place). The complete procedure for temperature calibration is detailed in a previous work ${ }^{15}$. It merges four independent methods to define the real bulk temperature of the sample. In the first method, the sample is heated with a conventional cartridge heater and the bulk sample temperature, measured with a thermocouple, is compared with the surface temperature given by the infrared pyrometer. The second method relies on the temperature measurements performed with a fibre optic sensor. The fibre optic calibration procedure consisted of heating a sample of CGO (15 mm height, $10 \mathrm{~mm}$ diameter) within the microwave cavity comparing (1) the temperature measured by the fibre optic in contact with the sample and (2) the surface temperature given by the infrared pyrometer. The calibration was performed at atmospheric pressure, opening the reactor for inserting the fibre optic inside the CGO sample. Likewise, same results equally apply when the reactor is sealed under other gas atmospheres.

In the third method, pure salts with well-known transition temperatures $\left(\mathrm{Ag}_{2} \mathrm{SO}_{4}\right.$ and $\left.\mathrm{KClO}_{4}\right)$ were heated in the microwave cavity and their dielectric properties were continuously monitored to identify the transition temperatures, which were employed to determine the relationship between the bulk temperature and the surface temperature at these points (see Supplementary Fig 10). The same procedure is applied in the fourth method but employing reference materials with wellknown Raman shifts at certain transition temperatures $\left(\mathrm{Bi}_{4} \mathrm{Ti}_{3} \mathrm{O}_{12}\right.$ and $\left.\mathrm{K}_{2} \mathrm{SO}_{4}\right)$.

Microwave-driven reaction experiments. Approximately $2.5 \mathrm{~g}$ of CGO powder sample $(\sim 1.2$ $\mathrm{cm}^{3}$ ) was placed on top of a quartz porous frit in a $10 \mathrm{~mm}$ internal diameter quartz tube $(1 \mathrm{~mm}$ wall thickness and $200 \mathrm{~mm}$ total height) and inserted within the cylindrical microwave cavity to irradiate materials and simultaneously (in situ) measure the conductivity. An infrared thermometer was used to measure temperature in the sample zone. The design of the cavity ensured temperature uniformity. The samples were measured with different carrier/reaction gases (that is, $\mathrm{CO}_{2}$, argon, $\mathrm{N}_{2}, \mathrm{CH}_{4}$ and mixtures $\mathrm{O}_{2} / \mathrm{N}_{2}$ ) with a flow rate of $100 \mathrm{ml} \mathrm{min}{ }^{-1}(\mathrm{NTP})$ in wet and dry conditions. The CGO reduction experiments were carried out in a $1 \% \mathrm{O}_{2} / \mathrm{N}_{2}$ carrier flow, which is sufficient to reoxidize the material. The reduction of $\mathrm{H}_{2} \mathrm{O}$ (saturated at $25^{\circ} \mathrm{C}, p_{H 2 O}=0.03$ atm) and subsequent reoxidation of $\mathrm{CGO}$ was made with a wet $\mathrm{N}_{2}$ sweeping, whereas the reduction of $\mathrm{CO}_{2}$ needed argon as a sweep, as the $\mathrm{CO}_{2}$ fraction masses overlap with those of $\mathrm{N}_{2}$. The gases were fed at atmospheric pressure through mass-flow controllers (Bronkhorst). The sample was heated up by microwaves in the cavity. The outlet gas flow was analysed in a mass spectrometer, following $2,4,12,13,14,16,17,18,20,28,29,32,40,43,44$ and 45 mass signals $(\mathrm{m} / \mathrm{z})$. Before the measurements, the sample powder packed-bed reactor was pretreated in situ by heating with microwave radiation in a flowing oxidizing atmosphere passing through a filter (SGT 
$\mathrm{CO} 1051)$ to remove adsorbed water, $\mathrm{CO}_{2}$ and other products that might have interfered with the measured species, and subsequently cooled down to room temperature.

The Sabatier reaction for catalytic methane synthesis was carried out in a two-step sequential process: (1) a constant flow rate of $100 \mathrm{ml} \mathrm{min}^{-1}$ of a gas mixture consisted of $15 \% \mathrm{CO}_{2}$ and $3 \%$ $\mathrm{H}_{2} \mathrm{O}$ (saturated at $25^{\circ} \mathrm{C}$ ) in argon was continuously circulated through the CGO fixed-bed reactor, which was activated by microwave irradiation at $35 \mathrm{~W} \mathrm{~g} \mathrm{~g}^{-1}$, and (2) the Sabatier reaction was conducted on-line in a second reactor. The reaction between the $\mathrm{CO}$ and $\mathrm{H}_{2}$ produced from $\mathrm{CO}_{2}$ and $\mathrm{H}_{2} \mathrm{O}$ deoxygenation was catalysed over $5 \% \mathrm{Ru} @ \gamma-\mathrm{Al}_{2} \mathrm{O}_{3}$ at $350{ }^{\circ} \mathrm{C}$. The catalyst was previously shaped into particles ranging from 0.25 to $0.35 \mathrm{~mm}$, and $350 \mathrm{mg}$ of catalyst was loaded into the methanation reactor. The catalyst was prereduced in $10 \% \mathrm{H}_{2}$ in $\operatorname{argon}$ at $350{ }^{\circ} \mathrm{C}$ for $2 \mathrm{~h}$. A control methanation reaction without catalyst was also performed.

Microwave-triggered oxidative conversion of $\mathrm{CH}_{4}$ into syngas over $\mathrm{CGO}$ was carried out at constant flow rate $\left(100 \mathrm{ml} \mathrm{min}^{-1}\right)$ of $10 \% \mathrm{CH}_{4}$ in argon. The oxide sample was irradiated at $35 \mathrm{~W}$ $\mathrm{g}^{-1}$, and the outlet gas was analysed by a mass spectrometer.

To quantify the released or formed species in the reactions, the gases in the mass spectrometer were calibrated $\left(\mathrm{O}_{2}, \mathrm{H}_{2}, \mathrm{CH}_{4}, \mathrm{CO}\right.$ and $\left.\mathrm{CO}_{2}\right)$. Pure $\mathrm{N}_{2}$ was used as the carrier gas at a flow rate of $100 \mathrm{ml} \mathrm{min}{ }^{-1}$ (NTP), except for $\mathrm{CO}$ due to mass overlapping. The response to gas/ $\mathrm{N}_{2}$ pulses (1 $\mathrm{ml}$ ), with different gas contents (from 0.01 to $100 \%, 4$ to 6 calibration points per gas) passing through the empty reactor, was analysed by on-line mass spectrometry. A six-port valve with a sample loop was used for injection of the $\mathrm{O}_{2} / \mathrm{Ar}$ pulses into the $\mathrm{N}_{2}$ carrier gas flow stream. Calibration gas bottles (purity 5.0) were purchased from Linde. Five pulses were measured for each of the gas contents and the average area of the peaks was calculated (with a relative error of $3 \%)$. The area was afterwards related to the gas yield or concentration.

Physicochemical characterization. X-ray diffraction measurements were carried out by a PANalytical Cubix fast diffractometer, using $\mathrm{CuK}_{\alpha 1}$ radiation $(\lambda=1.5406 \AA)$ and $\mathrm{X}^{\prime}$ Celerator detector in Bragg-Brentano geometry. X-ray diffraction patterns recorded in the $2 \theta$ range from $2^{\circ}$ to $90^{\circ}$ were analysed using X'Pert Highscore Plus software. UV-vis spectra of the compounds were recorded on a Varian 5000 UV-vis-NIR spectrophotometer in the range of 200-800 nm using $\mathrm{BaSO}_{4}$ as a reference material and with a lamp change at $350 \mathrm{~nm}$. Kubelka-Munk $(\mathrm{K}-\mathrm{M})$ theory has been used to estimate the energy gap Eg of the material ${ }^{49,50}$. The evaluation involves plotting of the obtained $\left(h v F(R \infty)^{2}\right)$ as a function of $h v$. In ceria ${ }^{51}$, the difference between the conduction and $4 f$ electrons states can be estimated by extrapolating a tangent line drawn in the point of inflection of the curve to zero. X-Ray Photoelectron spectra (XPS) were recorded on a SPECS spectrometer with a MCD-9 detector by using non-monochromatic AlKa radiation $(1,486.6 \mathrm{eV})$ of a twin anode in the constant analyser energy mode, with a pass energy of $50 \mathrm{eV}$ and an X-ray power of $100 \mathrm{~W}$ under an operating pressure of $10^{-9} \mathrm{mbar}$. The binding energy scale 
was regulated by setting the $\mathrm{C} 1 \mathrm{~s}$ transition at $284.6 \mathrm{eV}$. The accuracy of the binding energy was $0.1 \mathrm{eV}$. During data processing of the XPS spectra, binding energy values were referenced to the oxygen $1 s$ peak of the $\mathrm{CeO} 2$ lattice settled at $530 \mathrm{eV}$. The energy regions of cerium $3 d, \mathrm{O} 1 s$ and C $1 s$ transitions were recorded. Spectra analyses were performed using CasaXPS software v. 2.3.16Dev52 (http://www.casaxps.com). The samples were removed from the reactor under a flow of helium, quenched in liquid nitrogen, and transferred under $\mathrm{N}_{2}$ flow into the XPS spectrometer to avoid the reoxidation of the material. Temperature-programmed reduction was carried out in a Micromeritics system. $100 \mathrm{mg}$ of sample were degassed under argon flow for $1 \mathrm{~h}$ and subjected to reduction under $\mathrm{H}_{2} / \mathrm{Ar}(1 / 9)$ flow, by a heating rate of $10{ }^{\circ} \mathrm{C} \mathrm{min}{ }^{-1}$ until $950{ }^{\circ} \mathrm{C}$. The $\mathrm{H}_{2}$ consumption was measured by a thermal-conductivity detector.

Thermodynamic evaluation. The complete loop of hydrogen generation due to microwaveinduced oxygen vacancy generation involves the water dissociation through two phenomena: (1) microwave-assisted oxygen generation and the formation of oxygen vacancies in the lattice, and (2) hydrogen generation by the oxidation of these oxygen vacancies with the oxygen from water. The second step means the spontaneous formation of hydrogen by the reoxidation of the material with steam. The equilibrium of the release of $\mathrm{H}_{2}$ generation could be expressed in terms of lattice terms,

$$
2 \mathrm{Ce}_{\mathrm{Ce}}^{\prime}+\mathrm{V}_{\mathrm{O}}^{\ddot{2}}+\mathrm{H}_{2} \mathrm{O} \rightleftarrows 2 \mathrm{C} e_{\mathrm{Ce}}^{X}+\mathrm{O}_{O}^{X}+\mathrm{H}_{2},
$$

Therefore, for the evaluation of the equilibrium of this reaction, the Gibbs free energy is related to the reactant's concentrations through the equilibrium ratio of the reaction:

$$
K_{E Q} \equiv \exp \left(-\frac{\Delta G_{r H_{2}}}{R T}\right)=\frac{\left[O_{O}^{X}\right] \cdot\left[C e_{C e}^{X}\right]^{2} \cdot p_{H_{2}}}{\left[V_{O}^{*}\right] \cdot\left[C e_{C e}^{\prime}\right]^{2} \cdot p_{H_{2} O}}
$$

The extended thermodynamic modelling methodology is explained in the Supplementary Methods.

Evaluation of the energy cost and generated hydrogen. The efficiency analysis in hydrogen generation process is evaluated considering the energy demand of the process regarding the HHV. For hydrogen, the $\mathrm{HHV}$ is $283.6 \mathrm{~kJ} \mathrm{~mol}^{-1}$. The energy demand was evaluated under two scenarios: (case 1) considering only the electric demand of the process and (case 2) considering both the heat and the electric demands. As microwave heating is inherent to the assisted reduction of the material, the entropic heat demand of this reaction is generally covered. A more detailed thermodynamic modelling methodology is set forth in the Supplementary Methods. 


\section{Data availability}

The data used in this study are presented in the text, Supplementary Information and Source Data. Additional data and information are available from the corresponding author on request. Source data are provided with this paper.

\section{Acknowledgments}

This work was supported by the Spanish Government (RTI2018-102161, SEV-2016-0683 and Juan de la Cierva grant IJCI-2017-34110). We thank the support of the Electronic Microscopy Service of the Universitat Politècnica de València.

\section{Author contributions}

J.F.B.-M, P.P.-G., L.N and B.G.-B. performed the experiments. J.M.S., J.M.C.-C., M.B. and B.G.-B. designed the experiments. J.M.C.-C. and P.P.-G designed and fabricated the microwavecavity assembly. J.F.B.-M, P.P.-G., B.G.-B., J.S.-B., and J.M.C.-C. analysed electrochemical and physical data. M.B, L.N., J.F.B.-M. and J.M.S performed the gas analyses and evaluated catalytic data. D.C.-M. performed thermodynamic and process simulations. M.B. collected physicochemical characterization. J.M.S. and J.M.C.-C. initiated the project. J.M.S., J.M.C.-C., L.N., J.S.-B., D.C.-M. and M.B. wrote the manuscript, whereas all authors discussed the results and commented on the manuscript.

\section{Competing interests}

The Universitat Politècnica de València and Consejo Superior de Investigaciones Científicas have jointly applied for a patent based on the method for microwave-driven reduction of oxides and its uses. The inventors are J.M.S., J.F.B.M., B.G.B., J.M.C.C. and L.N.A. and the Spanish priority number is ES2726028-B2.

\section{Additional information}

Supplementary information is available for this paper at https://doi.org/10.1038/ s41560-02000720-6.

Correspondence and requests for materials should be addressed to J.M.S. or J.M.C.-C

Reprints and permissions information is available at www.nature.com/reprints. 


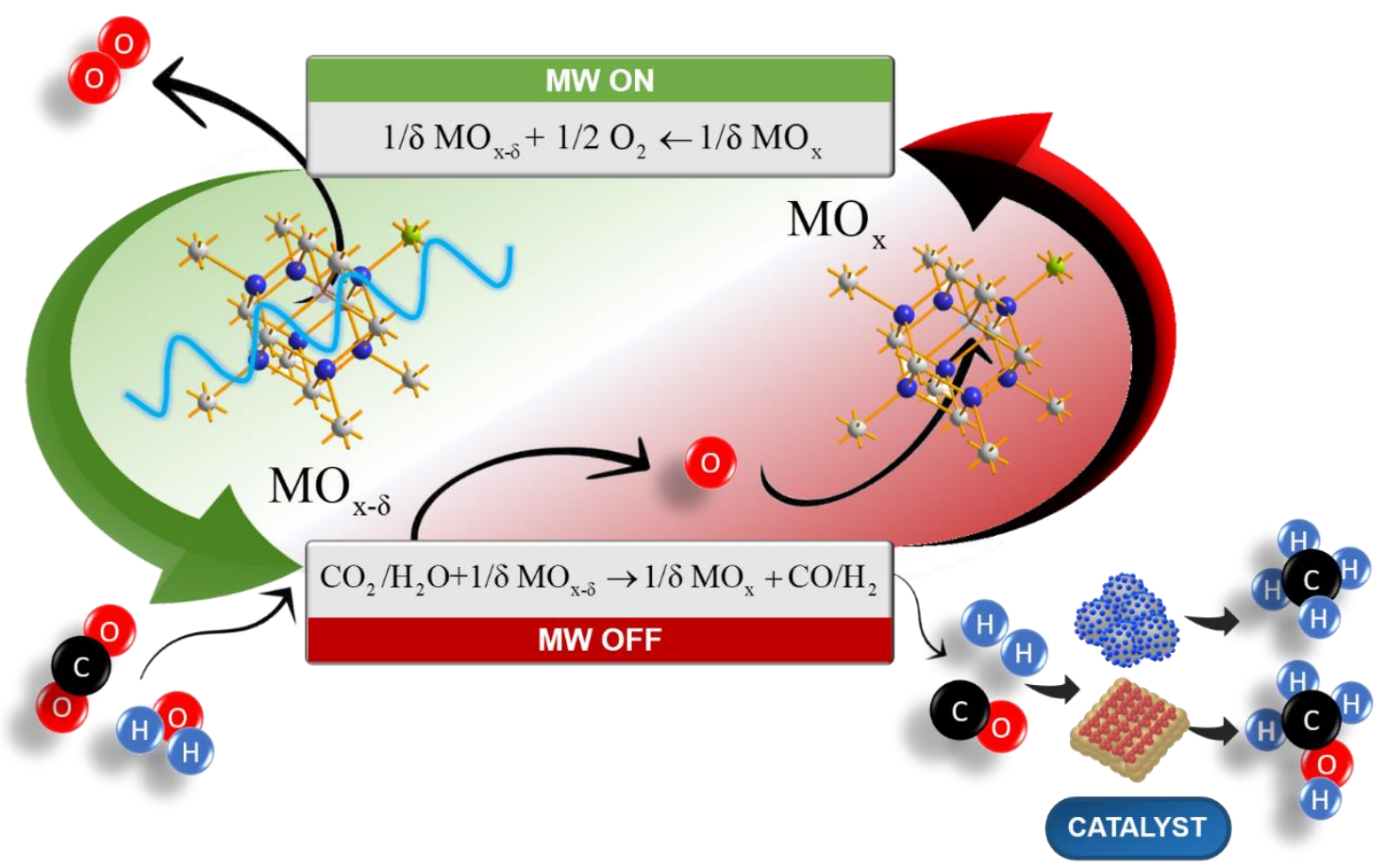

Fig. 1 | Schematic illustration of the microwave-induced redox cycle. Microwave irradiation of doped ceria materials induce its reduction and triggers the release of gaseous oxygen. The input of a suitable sweep gas on microwave switching-off leads to the material reoxidation via gas deoxygenation and the formation of valuable molecular energy carriers. MW, microwave. 

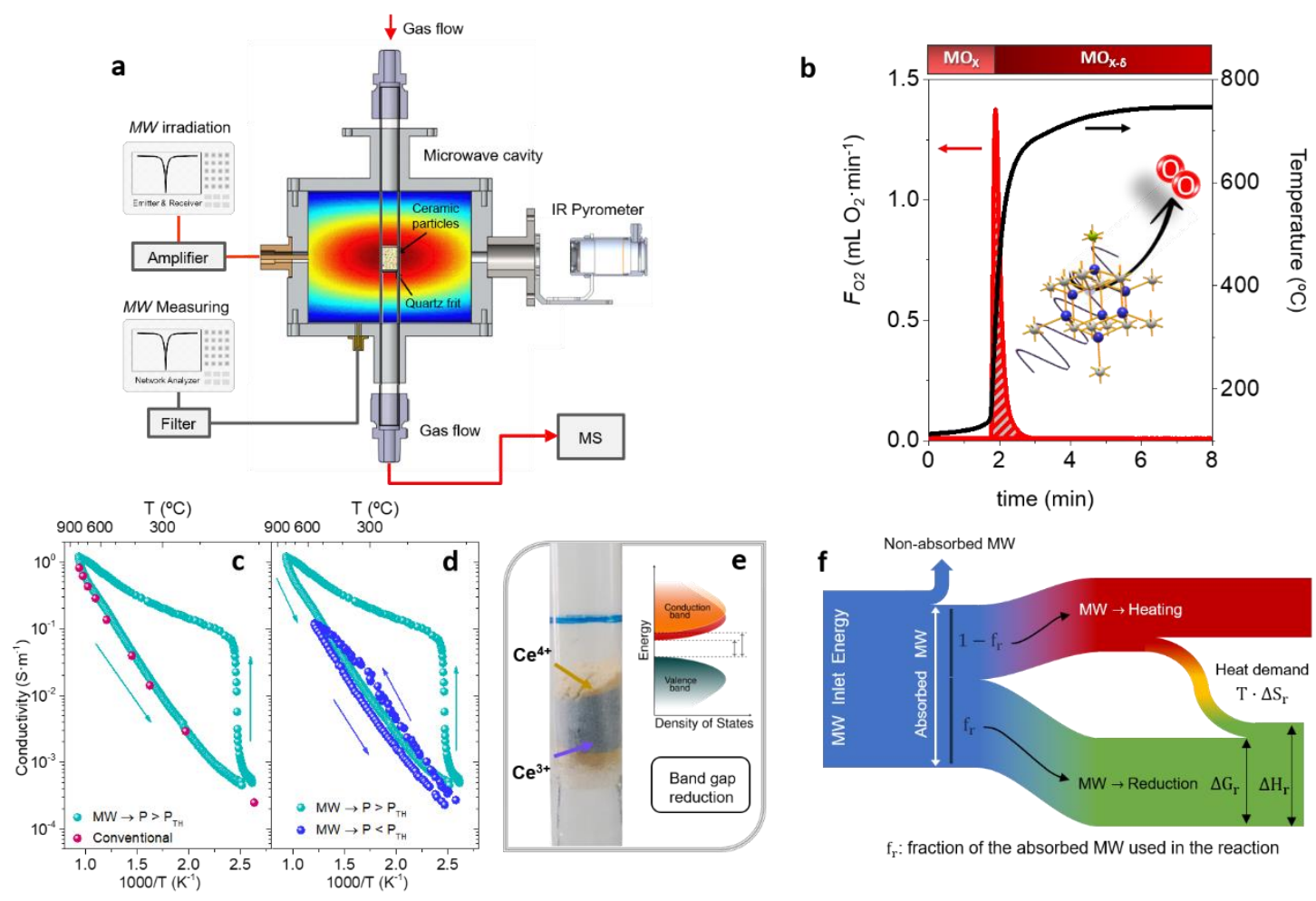

Fig. 2 | Microwave radiation process induces reduction of $\mathrm{Ce}^{4+}$ in $\mathrm{CeO}_{2}$. a, Experimental setup for microwave irradiation $(120 \mathrm{~W})$ and simultaneous measurement of alternating current conductivity, illustrating the theoretical (modelled) $\mathrm{TE}_{111}$ relative electromagnetic field distribution inside of the resonant cavity (see colour mapping) at $25^{\circ} \mathrm{C}$, in ambient air, with a maximum value $\sim 8.104 \mathrm{~V} \mathrm{~m}^{-1}$. b. During the microwave irradiation of CGO (2.4 g) sintered at $1,400{ }^{\circ} \mathrm{C}$ and the associated heating, the mass spectrometry analysis reveals sudden oxygen release per unit time $\left(F_{O 2}\right)$ after reaching a characteristic $T_{i n d}$ and $P_{t h}$. Tests were performed under dry $\mathrm{N}_{2}$ flow for a controlled absorbed power $\left(P_{M W} \approx 30 \mathrm{~W} \mathrm{~g}^{-1}\right)$ after reaching $T_{\text {ind. }}$. c, Electrical alternating current conductivity as a function of reciprocal temperature characterizes the effect of microwave irradiation in the material charge-carrier conduction in CGO under $\mathrm{N}_{2}$ flow. The microwave-induced reduction is triggered for supplied powers above the material power threshold, showing an abrupt electrical conductivity step enhancement. The upwards (downwards) arrows indicate material heating up (cooling down) in the presence (absence) of microwaves. The thermal behaviour of the conduction in the unreduced material with no irradiation is included for comparison. d, The conductivity Arrhenian plots display distinctive thermal behaviours in CGO for supplied microwave powers above and below the material power threshold under dry $\mathrm{N}_{2}$ flow. Although an abrupt electrical conductivity step enhancement and material reduction are only reported in the first scenario, the microwave irradiation also boosts the charge-carrier mobility in the unreduced case, as the different heating up and cooling down patterns unveil. e, The reduction of CGO is detected macroscopically by the change in colour of the powder, turning from blue to yellow as it oxidizes in contact with ambient air. The inset shows that the colour variation is caused by the energy gap contraction of the lowest $4 f$ state to the valence band in reduced ceria. f, A Sankey diagram of the energy process in the material reduction. The microwave energy is absorbed by both the material reduction $\left(f_{r}\right)$ and heating (1$f_{r}$ ) processes. The entropic demands for the generation of oxygen vacancies can be covered by excess heat. 

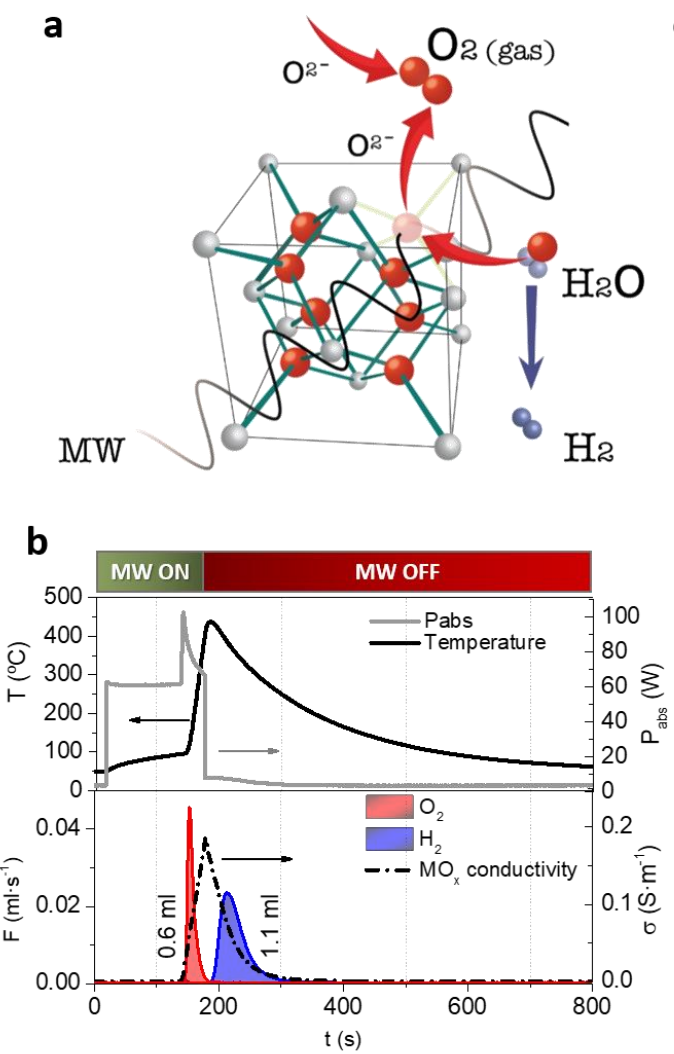

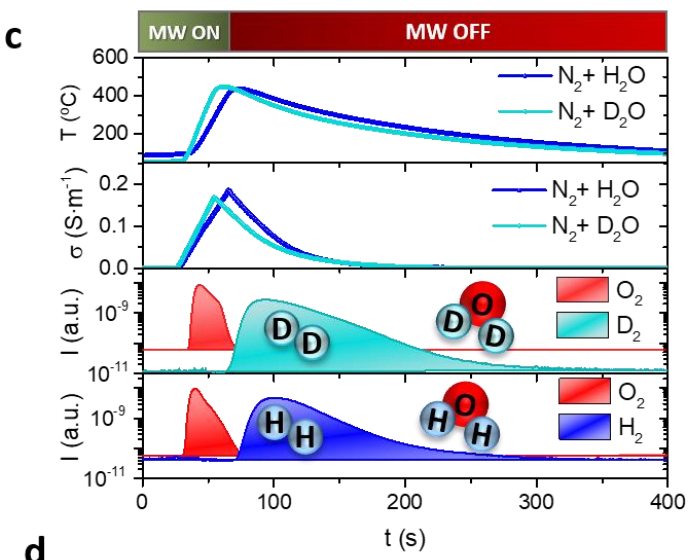

d

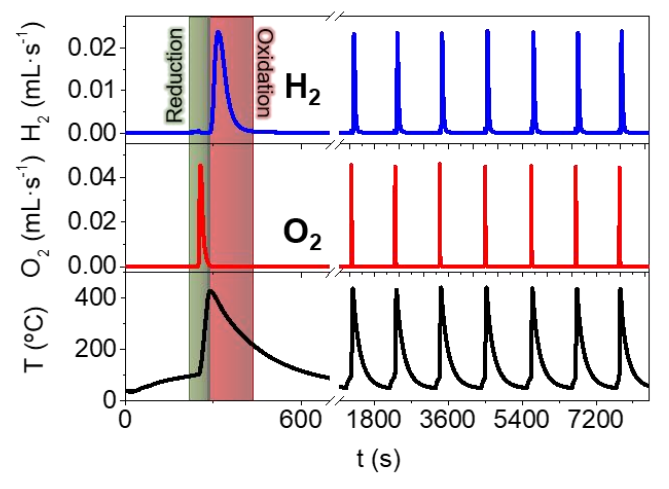

Fig. 3 | Application and time sequence in water deoxygenation. a, Schematics of the $\mathrm{H}_{2} \mathrm{O}$ reduction mechanism through the extraction of one oxygen atom that is reduced to $\mathrm{O}^{2-}$ and accommodated into the lattice of the reduced oxide (crystalline host), converting an oxygen vacancy (VO“) into a neutral oxygen site (OX). b, A time sequence of the control parameters in the reduction process shows stepwise behaviour, by the time oxygen is released; once microwaves are switched off, hydrogen is formed. c, A time-sequence comparison of the reduction process under $\mathrm{H}_{2} \mathrm{O}$ (dark blue) and $\mathrm{D}_{2} \mathrm{O}$ (light blue) mixed with $\mathrm{N}_{2}$ flow displays similar values for (from top to bottom) temperature, conductivity $(\sigma), \mathrm{D}_{2}$ yield and $\mathrm{H}_{2}$ yield. d, The production of $\mathrm{H}_{2}$ via water splitting is prompted by the reoxidation of CGO material on the microwave switching off. Cyclability is accomplished by the alternate presence and absence of microwave radiation under a $\mathrm{N}_{2}$ gas flow saturated with $\mathrm{H}_{2} \mathrm{O}$ at $25^{\circ} \mathrm{C}\left(3 \% \mathrm{H}_{2} \mathrm{O}\right.$ in $\left.\mathrm{N}_{2}\right)$. 

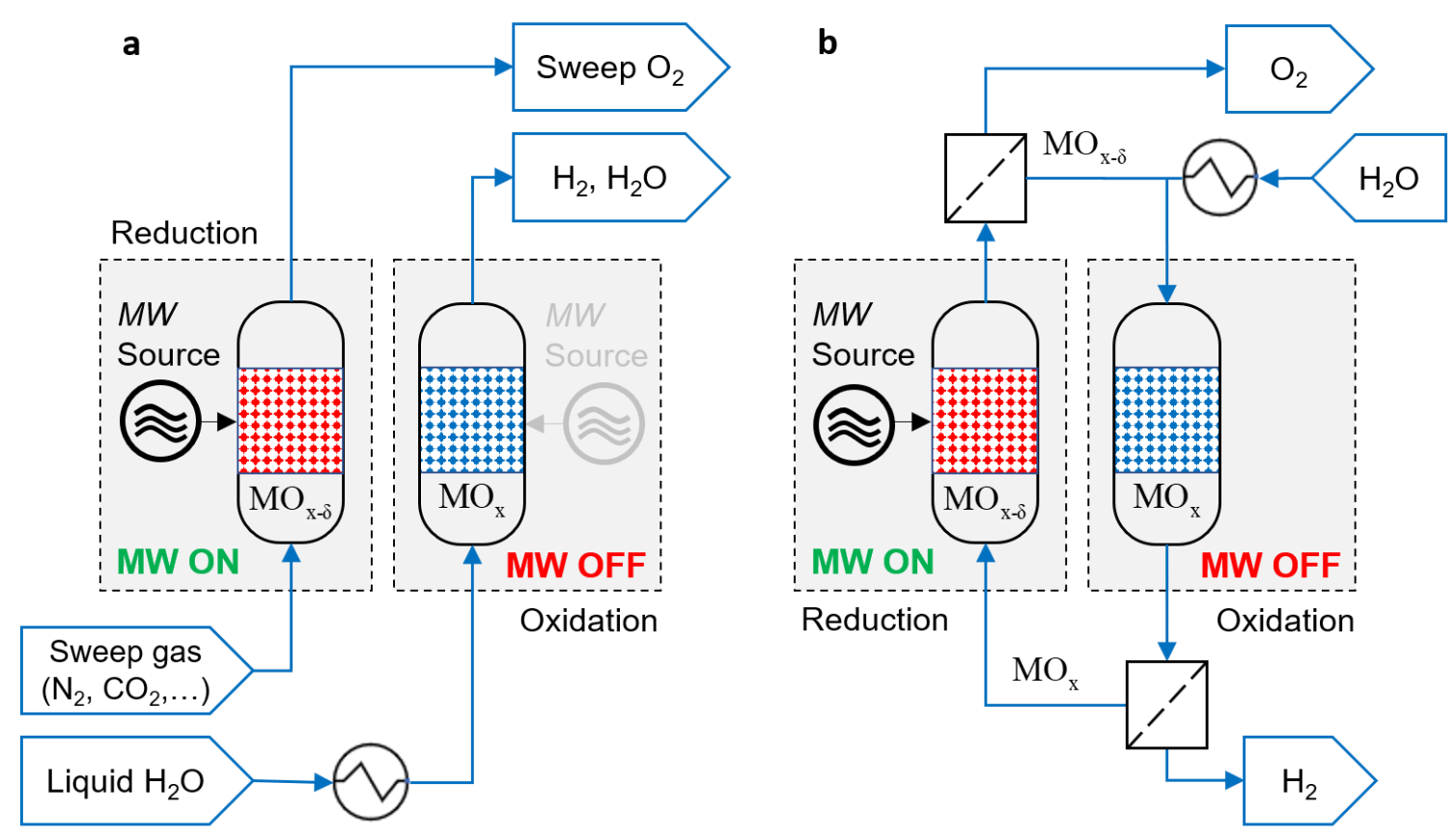

Fig. 4 Hydrogen production flowchart based on microwave reduction. a,b, A comparison of the swing reactor (a) and the chemical loop (b) configurations for microwave-induced hydrogen production. Microwave irradiation is periodically alternated between two independent reactors in $\mathbf{a}$, as opposed to the sequential disposition of the reduction and the oxidation reactors in $\mathbf{b}$. 


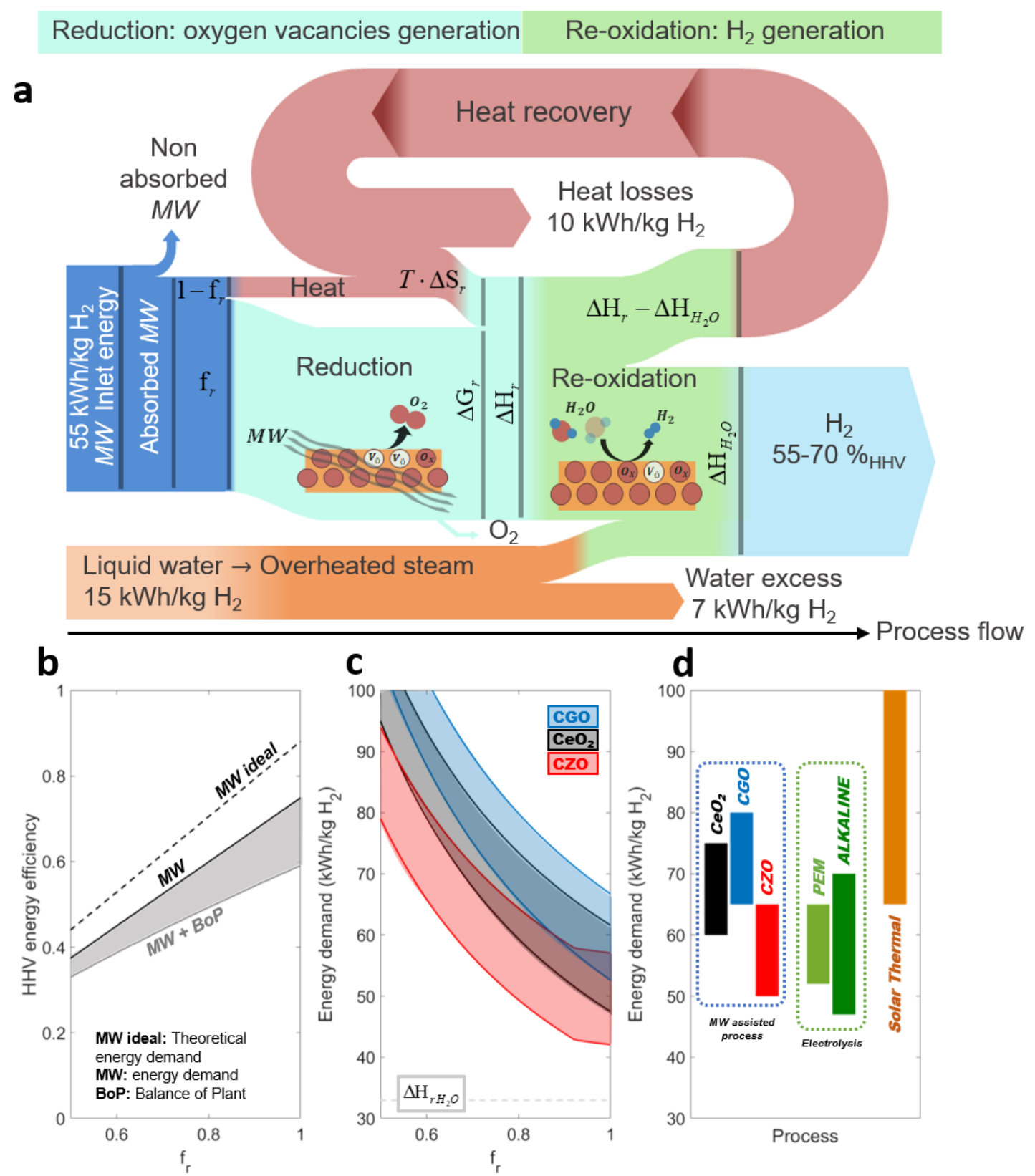

Fig. 5 | Energy balance and efficiency for hydrogen production. a, A Sankey energy diagram of the energy distribution of the complete microwave-assisted redox cycle for hydrogen production. The heat excess from CGO reoxidation is reused to supply the energy demand of the reduction step. b. Energy efficiency and $\mathrm{H}_{2}$ energy cost as a function of the microwave-toreduction effectiveness for the reduction process $\left(f_{r}\right)$ favour higher values of this parameter, for different ceria-based materials. The here presented microwave-induced process may improve the current $\mathrm{H}_{2}$ energy production costs and outperform the state-of-the-art technologies for hydrogen generation. The energy efficiency is evaluated considering the high heating value (HHV) for the $\mathrm{H}_{2}$ generation with CGO in a loop process. c, $\mathrm{H}_{2}$ energy cost-evaluated for $\mathrm{CGO}, \mathrm{CeO}_{2}$ and $\mathrm{CZO}$ materials considering the microwave electric demand and the balance of plant heats considering reduction and reoxidation at $350{ }^{\circ} \mathrm{C}$. $\mathbf{d}$, A comparison with conventional technologies evaluated on the same basis: PEM electrolysis ${ }^{30-34}$, alkaline electrolysis ${ }^{28-33}$ and solar thermal ${ }^{32,35-45}$. Heat losses, 5\%; water excess, $100 \%$; power-to-microwave efficiency, $85 \%$; non-absorbed microwave power, $5 \% ; \Delta \delta_{\text {loop }} \equiv \delta_{r}-\delta_{o x}=0.002-0.005 ; \Delta H_{r, \mathrm{H} 2 \mathrm{O}}$, enthalpy of the water dissociation. 

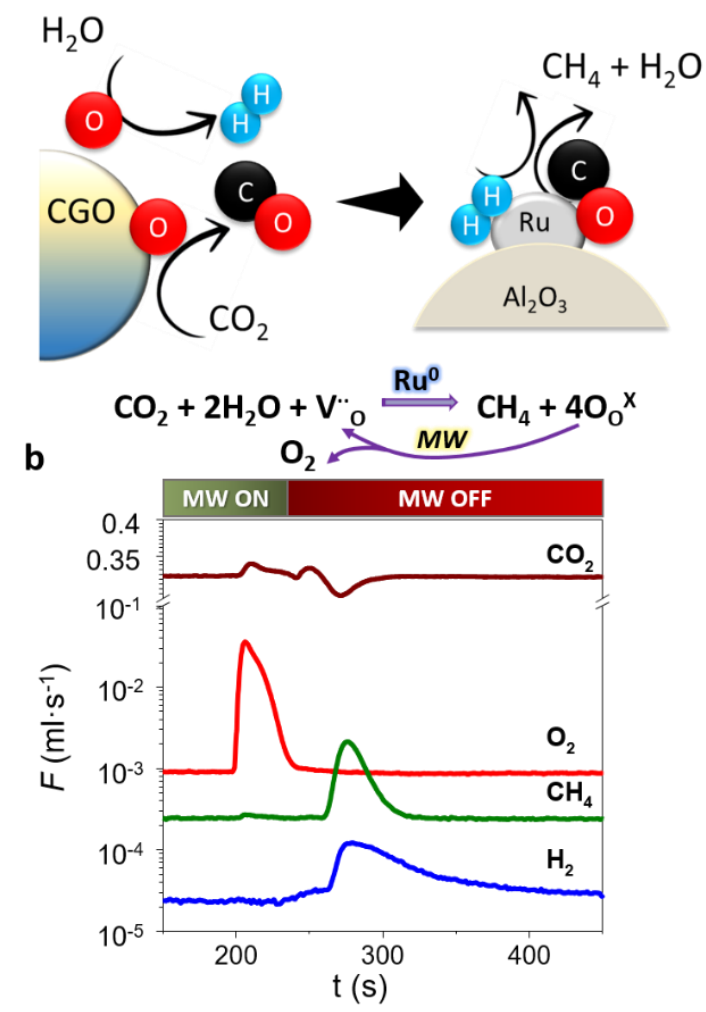

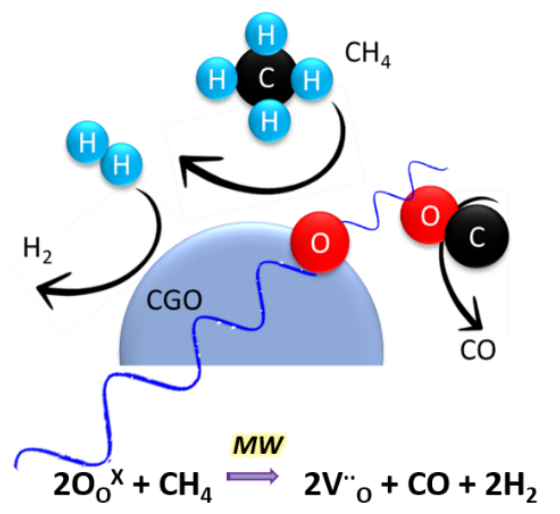

d

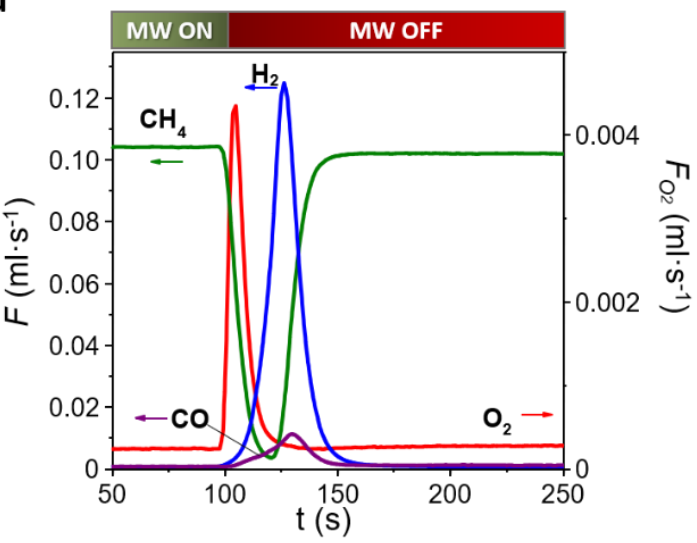

Fig. 6 | Microwave electrocatalysis in energy conversion reactions. a, Schematics of $\mathrm{CH}_{4}$ formation by in-series coupling of $\mathrm{CO}_{2}$ and $\mathrm{H}_{2} \mathrm{O}$ deoxygenation over redox-activated CGO (left) and the Sabatier reaction catalysed over 5\% Ru@ $\gamma-\mathrm{Al}_{2} \mathrm{O}_{3}$ at $350{ }^{\circ} \mathrm{C}$ (right). bo, Time monitoring of $\mathrm{CGO}$ activation (maximum absorbed power, $35 \mathrm{~W} \mathrm{~g}^{-1}$ ) and subsequent $\mathrm{CH}_{4}$ synthesis. A constant flow rate $\left(100 \mathrm{ml} \mathrm{min}^{-1}\right)$ of a gas mixture $\left(3 \% \mathrm{H}_{2} \mathrm{O}, 15 \% \mathrm{CO}_{2}\right.$ in argon) was passed through the first CGO fixed-bed reactor. c, Schematics of the all-at-once CGO microwavetriggered reduction and oxidative conversion of $\mathrm{CH}_{4}$ into syngas. The irradiated oxide is polarized, becoming more redox-active but also forming oxygen species on its surface that subsequently react with adsorbed $\mathrm{CH}_{4}$ to form $\mathrm{H}_{2}$ and $\mathrm{CO}$. d, Time sequence of the production of $\mathrm{H}_{2}$ and $\mathrm{CO}$ from $\mathrm{CH}_{4}$ oxidation on $\mathrm{CGO}$ reduction at maximum absorbed power $35 \mathrm{~W} \mathrm{~g}^{-1}$. A constant flow rate $\left(100 \mathrm{ml} \mathrm{min}^{-1}\right)$ of a gas mixture $\left(3 \% \mathrm{H}_{2} \mathrm{O}, 10 \% \mathrm{CH}_{4}\right.$ in argon) was continuously circulated through the CGO fixed-bed reactor. 


\section{References}

1. Serra, J. M. Electrifying chemistry with protonic cells. Nat. Energy 4, 178-179 (2019).

2. Wei, M., McMillan, C. A. \& de la Rue du Can, S. Electrification of Industry: Potential, Challenges and Outlook. Curr. Sustain. Energy Reports 6, 140-148 (2019).

3. Malerød-Fjeld, H. et al. Thermo-electrochemical production of compressed hydrogen from methane with near-zero energy loss. Nat. Energy 2, (2017).

4. Schiffer, Z. J. \& Manthiram, K. Electrification and Decarbonization of the Chemical Industry. Joule 1, 10-14 (2017).

5. Ran, J., Zhang, J., Yu, J., Jaroniec, M. \& Qiao, S. Z. Earth-abundant cocatalysts for semiconductor-based photocatalytic water splitting. Chem. Soc. Rev. 43, 77877812 (2014).

6. Kudo, A. \& Miseki, Y. Heterogeneous photocatalyst materials for water splitting. Chem. Soc. Rev. 38, 253-278 (2009).

7. Vøllestad, E. et al. Mixed proton and electron conducting double perovskite anodes for stable and efficient tubular proton ceramic electrolysers. Nat. Mater. 18, 752-759 (2019).

8. Duan, C. et al. Highly efficient reversible protonic ceramic electrochemical cells for power generation and fuel production. Nat. Energy 4, 230-240 (2019).

9. Service, R. F. New electrolyzer splits water on the cheap. Science (80-. ). 367, 1181 (2020).

10. Hamzehlouia, S., Jaffer, S. A. \& Chaouki, J. Microwave Heating-Assisted Catalytic Dry Reforming of Methane to Syngas. Sci. Rep. 8, 8940 (2018).

11. Tsukahara, Y. et al. In situ observation of nonequilibrium local heating as an origin of special effect of microwave on chemistry. J. Phys. Chem. C 114, 89658970 (2010).

12. Sholl, D. S. \& Lively, R. P. Seven chemical separations to change the world. Nature vol. 532 435-437 (2016).

13. Eigen, J. \& Schroeder, M. Redox cycling stability of Fe2NiO4/YSZ composite storage materials for rechargeable oxide batteries. Energy Storage Mater. 28, 112-121 (2020).

14. Catalá-Civera, J. M. et al. Dynamic Measurement of Dielectric Properties of Materials at High Temperature During Microwave Heating in a Dual Mode 
Cylindrical Cavity. IEEE Trans. Microw. Theory Tech. 63, 2905-2914.

15. García-Baños, B., Reinosa, J. J., Peñaranda-Foix, F. L., Fernández, J. F. \& CataláCivera, J. M. Temperature Assessment Of Microwave-Enhanced Heating Processes. Sci. Rep. 9, 10809 (2019).

16. Campbell, C. T. \& Peden, C. H. F. Oxygen vacancies and catalysis on ceria surfaces. Science (80-. ). 309, 713-714 (2005).

17. Naghavi, S. S. et al. Giant onsite electronic entropy enhances the performance of ceria for water splitting. Nat. Commun. 8, 1-6 (2017).

18. Chueh, W. C. et al. High-flux solar-driven thermochemical dissociation of $\mathrm{CO} 2$ and $\mathrm{H} 2 \mathrm{O}$ using nonstoichiometric ceria. Science (80-. ). 330, 1797-1801 (2010).

19. Bulfin, B. et al. Analytical model of $\mathrm{CeO} 2$ oxidation and reduction. J. Phys. Chem. C 117, 24129-24137 (2013).

20. Geller, A. et al. Operando Tracking of Electrochemical Activity in Solid Oxide Electrochemical Cells by using Near-Infrared Imaging. ChemElectroChem 2, 1527-1534 (2015).

21. Balaguer, M., Solís, C. \& Serra, J. M. Structural-transport properties relationships on Ce 1- xLn xO 2- $\delta$ system ( $L n=G d, L a, T b, P r, E u, E r, Y b, N d$ ) and effect of cobalt addition. J. Phys. Chem. C 116, 7975-7982 (2012).

22. Holstein, T. Studies of polaron motion. Part II. The 'small' polaron. Ann. Phys. (N. Y). 8, 343-389 (1959).

23. Seki, K. \& Tachiya, M. Electric field dependence of charge mobility in energetically disordered materials: Polaron aspects. Phys. Rev. B - Condens. Matter Mater. Phys. 65, 1-13 (2002).

24. Emin, D. Generalized adiabatic polaron hopping: Meyer-neldel compensation and poole-frenkel behavior. Phys. Rev. Lett. 100, 166602 (2008).

25. Bishop, S. R., Duncan, K. L. \& Wachsman, E. D. Surface and bulk oxygen nonstoichiometry and bulk chemical expansion in gadolinium-doped cerium oxide. Acta Mater. 57, 3596-3605 (2009).

26. Suzuki, T., Kosacki, I. \& Anderson, H. U. Defect and Mixed Conductivity in Nanocrystalline Doped Cerium Oxide. J. Am. Ceram. Soc. 85, 1492-1498 (2002).

27. Zeng, L., Cheng, Z., Fan, J. A., Fan, L. S. \& Gong, J. Metal oxide redox chemistry for chemical looping processes. Nature Reviews Chemistry vol. 2 349-364 (2018).

28. Liu, W., Song, M.-S., Kong, B. \& Cui, Y. Flexible and Stretchable Energy Storage: Recent Advances and Future Perspectives. Adv. Mater. 29, 1603436 (2017). 
29. Berger, C. M. et al. Development of storage materials for high-temperature rechargeable oxide batteries. J. Energy Storage 1, 54-64 (2015).

30. Posdziech, O., Schwarze, K. \& Brabandt, J. Efficient hydrogen production for industry and electricity storage via high-temperature electrolysis. Int. J. Hydrogen Energy 44, 19089-19101 (2019).

31. Maric, R. \& Yu, H. Proton exchange membrane water electrolysis as a promising technology for hydrogen production and energy storage. in Nanostructures in Energy Generation, Transmission and Storage (IntechOpen, 2018).

32. Dincer, I. \& Acar, C. Review and evaluation of hydrogen production methods for better sustainability. Int. J. Hydrogen Energy 40, 11094-11111 (2015).

33. Gielen, D. Hydrogen from Renewable Power Technology Outlook for the Energy Transition. (2018).

34. Kuckshinrichs, W., Ketelaer, T. \& Koj, J. C. Economic analysis of improved alkaline water electrolysis. Front. Energy Res. 5, 1 (2017).

35. Holladay, J. D., Hu, J., King, D. L. \& Wang, Y. An overview of hydrogen production technologies. Catalysis Today vol. 139 244-260 (2009).

36. Glenk, G. \& Reichelstein, S. Economics of converting renewable power to hydrogen. Nat. Energy 4, 216-222 (2019).

37. Marxer, D., Furler, P., Takacs, M. \& Steinfeld, A. Solar thermochemical splitting of $\mathrm{CO} 2$ into separate streams of $\mathrm{CO}$ and $\mathrm{O} 2$ with high selectivity, stability, conversion, and efficiency. Energy Environ. Sci. 10, 1142-1149 (2017).

38. Vogt, C., Monai, M., Kramer, G. J. \& Weckhuysen, B. M. The renaissance of the Sabatier reaction and its applications on Earth and in space. Nature Catalysis vol. 2 188-197 (2019).

39. Eckle, S., Anfang, H. G. \& Behm, R. J. Reaction intermediates and side products in the methanation of $\mathrm{CO}$ and $\mathrm{CO} 2$ over supported Ru catalysts in $\mathrm{H} 2$-rich reformate gases. J. Phys. Chem. C 115, 1361-1367 (2011).

40. Wei, Y. et al. Three-dimensionally ordered macroporous Ce 0.8Zr 0.2O 2supported gold nanoparticles: Synthesis with controllable size and supercatalytic performance for soot oxidation. Energy Environ. Sci. 4, 2959-2970 (2011).

41. Santos, V. P., Pereira, M. F. R., Órfão, J. J. M. \& Figueiredo, J. L. The role of lattice oxygen on the activity of manganese oxides towards the oxidation of volatile organic compounds. Appl. Catal. B Environ. 99, 353-363 (2010).

42. Hickman, D. A. \& Schmidt, L. D. Production of syngas by direct catalytic oxidation of methane. Science (80-. ). 259, 343-346 (1993). 
43. Feng, Z. A., El Gabaly, F., Ye, X., Shen, Z. X. \& Chueh, W. C. Fast vacancymediated oxygen ion incorporation across the ceria-gas electrochemical interface. Nat. Commun. 5, 1-9 (2014).

44. Flytzani-Stephanopoulos, M., Sakbodin, M. \& Wang, Z. Regenerative adsorption and removal of $\mathrm{H} 2 \mathrm{~S}$ from hot fuel gas streams by rare earth oxides. Science (80-. ). 312, 1508-1510 (2006).

45. Paunović, V. et al. Europium Oxybromide Catalysts for Efficient Bromine Looping in Natural Gas Valorization. Angew. Chemie Int. Ed. 56, 9791-9795 (2017).

46. Krupka, J. Contactless methods of conductivity and sheet resistance measurement for semiconductors, conductors and superconductors. Meas. Sci. Technol. 24, 62001 (2013).

47. Altschuler, H. M. Handbook of Microwave Measurements. vol. 2 (USA: Polytech. Inst. Brooklyn Press, 1963).

48. Arai, M., Binner, J. G. P. \& Cross, T. E. Comparison of Techniques for Measuring High-Temperature Microwave Complex Permittivity: Measurements on an Alumina/Zircona System. J. Microw. Power Electromagn. Energy 31, 12-18 (1996).

49. López, R. \& Gómez, R. Band-gap energy estimation from diffuse reflectance measurements on sol-gel and commercial TiO2: a comparative study. J. Sol-Gel Sci. Technol. 61, 1-7 (2012).

50. Murphy, A. B. Band-gap determination from diffuse reflectance measurements of semiconductor films, and application to photoelectrochemical water-splitting. Sol. Energy Mater. Sol. Cells 91, 1326-1337 (2007).

51. Skorodumova, N. V. et al. Electronic, bonding, and optical properties of $\mathrm{CeO} 2$ and Ce2O3 from first principles. Phys. Rev. B - Condens. Matter Mater. Phys. 64, 1151081-1151089 (2001). 